\title{
Perceptions of insulin therapy in people with type 2 diabetes and physicians: a cross-sectional survey conducted in France
}

This article was published in the following Dove Medical Press journal: Patient Preference and Adherence

\section{Emmanuel Cosson ${ }^{1,2}$ \\ Christine Mauchant ${ }^{3}$ \\ Imane Benabbad ${ }^{3}$ \\ Gilles Le Pape ${ }^{4}$ \\ Marion Le Bleis ${ }^{3}$ \\ Frédérique Bailleul ${ }^{3}$ \\ Jean-Daniel Lalau ${ }^{5,6}$}

'Department of EndocrinologyDiabetology-Nutrition, CRNHIdF, CINFO, Jean Verdier Hospital, Paris I 3 University, Sorbonne Paris Cité, AP-HP, Bondy, Paris, France; ${ }^{2}$ Nutritional Epidemiology Research Unit, UMR UII 53 INSERM/UI I I 25 INRA/CNAM/Paris I 3 University, Bobigny, Paris, France; ${ }^{3}$ Lilly France, Neuilly-sur-Seine, Paris, France;

${ }^{4}$ General Practice, Penmarch, France; ${ }^{5}$ Department of EndocrinologyDiabetology-Nutrition, Amiens University Medical Center, Amiens, France; ${ }^{6}$ PériTox Laboratory (UMR-I 0I), Jules Verne University of Picardy, Amiens, France
Correspondence: Emmanuel Cosson Service de Diabétologie-EndocrinologieNutrition, Hôpital Jean Verdier,

14 Avenue du Juillet, Bondy, Paris 93/40, France

Tel +33 I4802 6580

Email emmanuel.cosson@aphp.fr
Objective: To evaluate perceptions of people with type 2 diabetes (T2D) and treating physicians living in France toward insulin therapy.

Methods: Adults with T2D receiving oral glucose-lowering treatment alone ( $\mathrm{INS}^{-}$) or basal insulin for $\geq 2$ months $\left(\mathrm{INS}^{+}\right)$completed an online cross-sectional survey comprising 39 questions, including some regarding perceptions and fears of insulin therapy. Physicians were interviewed by telephone using eleven similar questions. The survey was designed by French clinicians experienced in treating diabetes and conducted under the auspices of an independent market-research agency. Results: The questionnaire was completed by 590 adults with T2D (two-thirds INS ${ }^{+}$) and 130 physicians (65 diabetologists/endocrinologists, 65 general practitioners). INS ${ }^{+}$adults reported fewer negative feelings and more positive feelings than $\mathrm{INS}^{-}$adults. Two-thirds of $\mathrm{INS}^{+}$adults reported that transitioning to insulin therapy was less difficult than expected. Overall, $44 \%$ of $\mathrm{INS}^{+}$adults and $26 \%$ of physicians reported a fear of diabetic complications as being important, and $80 \%$ of physicians and $21 \%$ of INS $^{+}$adults considered injections to be a major patient fear. Conclusion: Most people with T2D reported that transitioning to insulin therapy was less difficult than they had feared. People with T2D and physicians exhibited differing perceptions regarding the transition. Reasons for the apprehension surrounding the transition to insulin therapy in people with T2D need to be better identified. Support from insulin-treated peers may enable this transition to occur with fewer anxieties in insulin-naïve people with T2D.

Keywords: psychological insulin resistance, patient perceptions, physician perceptions, patientphysician relationship

\section{Introduction}

The initial treatment of people with type 2 diabetes (T2D) involves diet and oral glucose-lowering agents. With time, insulinopenia progresses, and many people with T2D require insulin therapy. ${ }^{1}$ However, the initiation of insulin therapy is a difficult transition for both people with T2D and health care professionals. ${ }^{2}$

People with T2D usually report a fear of injections ${ }^{3,4}$ and the restrictions these can place on their lifestyle, ${ }^{4,5}$ as well as concerns about the complications of insulin therapy, such as hypoglycemia ${ }^{4-6}$ and weight gain. ${ }^{4}$ Many people with T2D view the initiation of insulin treatment as a sign that their disease has progressed and that they are more likely to experience diabetic complications. ${ }^{4,5}$ Insulin initiation has been generally associated with negative emotions, fears, and anxiety, ${ }^{7,8}$ as well as a sense of personal failure. ${ }^{4,6,9}$

Resistance to initiating insulin therapy has also been described among physicians. Physicians' concerns center on the difficulties associated with first mentioning insulin, 
and then on how they will discuss and educate their patients with $\mathrm{T} 2 \mathrm{D}$ on why insulin may be needed, the techniques required to inject insulin, how to modify the insulin dose, and how to manage hypoglycemia. ${ }^{10,11}$

The reluctance to initiate insulin therapy among both physicians and people with T2D - described as "psychological insulin resistance"11-13 - means that insulin therapy may be delayed. Analyses from the DAWN study showed that in the US, most nurses and general practitioners (50\%-55\%) delayed insulin therapy until it was absolutely necessary. ${ }^{9}$ In a survey of 3,833 patients with diabetes, nearly $30 \%$ of 1,267 respondents reported being unwilling to take insulin if prescribed. ${ }^{6}$ In the UK Prospective Diabetes Study, the percentage of patients treated with insulin alone who were not taking their allocated medication (27\% of 676 patients) was double that of patients not taking their allocated oral medication (13\% of 446 patients taking chlorpropamide alone, $11 \%$ of 262 patients taking metformin alone, and $7 \%$ of 472 patients taking glibenclamide alone). ${ }^{14}$ As such, barriers to the initiation of insulin therapy in people with T2D, as well as their treating physicians, need to be more clearly delineated and better understood. Few studies have addressed this issue. The DAWN2 study, which aimed to assess psychosocial outcomes in adults with diabetes (both type 1 and type 2) and included 4,785 health care professionals caring for people with diabetes across 17 countries, found that $60 \%$ of these health care professionals indicated a need for a major improvement in diabetes self-management education. ${ }^{15}$ Such improvements were needed in most areas, including psychological support. ${ }^{15}$ However, this study did not assess the impact of insulin initiation. ${ }^{16}$ In France, no specific large study has assessed the perceptions of both people with $\mathrm{T} 2 \mathrm{D}$ and physicians regarding insulin therapy.

The current cross-sectional survey, designed by a group of experts familiar with treating people with T2D and conducted in France under the auspices of an independent market-research agency, aimed to evaluate the perceptions of French adults with T2D (both insulin-naïve and insulintreated) and their treating physicians toward insulin therapy.

\section{Methods}

\section{Design}

The cross-sectional survey was initiated by Lilly France and designed by a group of experts from France. This expert group comprised three diabetologists, two general practitioners, one nurse, and one psychologist. Participant recruitment, the online survey, and all telephone interviews were carried out under the auspices of an independent market-research agency that specializes in conducting surveys within France
(ViaVoice, Paris, France; http://www.institut-viavoice.com). This company adhered to industry standards prescribed by the European Society For Opinion and Marketing Research and the French association for market, opinion, and behavior research in health care (Association des Sociétés d'étude de l'Opinion et du Comportement dans le Domaine de la Santé).

People with T2D and physicians living in France were surveyed regarding their perceptions of insulin therapy. The online survey was designed to elicit information from people regarding their perceptions and fears related to insulin therapy. Initial testing of the survey among eight people with T2D led to minor wording changes in questions.

The survey aimed to include 600 people with T2D: 200 receiving oral glucose-lowering drug therapy and 400 receiving basal insulin therapy. Among the insulin-treated group, the objective was to include at least 100 people who had received insulin for 2-24 months, in order to have a sufficiently large cohort in whom the delay since the start of insulin treatment was short enough to minimize the risk of recall bias. In parallel, the survey aimed to include 130 physicians, evenly split between diabetologists/endocrinologists and general practitioners.

\section{Participants}

People with diabetes were selected by the independent agency conducting the survey from a consumer panel using a sampling questionnaire to identify the two target populations. People were included in the survey if: they had selfreported $\mathrm{T} 2 \mathrm{D}$, were aged over 18 years, and indicated that they were receiving oral antidiabetic drugs or had received basal insulin therapy for $\geq 2$ months or $\leq 10$ years, 11 months. Three subpopulations were identified from the surveyed population: people who had received insulin for 2-24 months (the focus of this analysis), those who had received insulin for $>24$ months but $\leq 5$ years, 11 months, and those who had received insulin for $>6$ years. People with T2D who were receiving fast-acting insulin or mixed insulin therapy were excluded.

Physicians were independently selected from the directory of the French National Medical Council (Conseil National de l'Ordre des Médecins) and randomly contacted by the independent market agency conducting the survey. Written informed consent was obtained from all participants before the survey was conducted. All participants received overall information on the topic of the research, and were given information on how the data from the survey would be used and that it would be anonymized and pooled. Participants had the right to withdraw from the survey at any time, as well as the right to access and change their own data. 
Under French law, this type of market-research survey does not require approval from an ethics committee. Nevertheless, the study was conducted in accordance with the Declaration of Helsinki. Participants were not compensated for their time.

\section{Surveys}

The patient survey comprised 39 questions in French requesting information on demographics and diabetes therapies, and included questions on feelings, perceptions, and fears of insulin therapy. Some questions required yes/no answers, and multiple answers were possible for other questions. For questions relating to feelings, respondents were asked to rate their answers, based on retrospective recall, using a Likert scale (ranging from 1 [least likely] to 10 [most likely]) under five headings: guilt, distress, detachment, reassurance, and willingness. The physician survey comprised eleven questions that were similar to those asked in the patient survey. The questions and response options included in both surveys (in French) are available in the Supplementary material.

\section{Patient survey}

People with T2D answered the survey questions online, which took an average of 20 minutes to complete. The online survey was launched on October 15, 2015, and was discontinued on November 27, 2015. The sponsor of the survey was not disclosed, in order to avoid bias. Respondents and their answers were anonymized.

\section{Physician interviews}

A trained interviewer read the questions of the survey to the physician during a phone interview. Interviewers were trained so that all questions were asked in the same manner, and on average the interview took 15 minutes to complete. Interviews were recorded for analysis and the recordings subsequently destroyed. Responders were informed that data would be aggregated and their names would not be disclosed. These interviews were performed between November 30, 2015 and December 22, 2015.

\section{Analysis}

Data were collected and reported to the expert group by ViaVoice. The analysis was exploratory in nature, and descriptive analysis was used to summarize patients' and physicians' perceptions of insulin therapy. Means and SD were used for continuous variables, and frequencies and percentages were used for categorical variables. There was no imputation of missing data, and no statistical tests were performed between groups. The expert group selected relevant data from the two surveys to assess the experiences and perceptions of insulin of people with T2D, as well as physicians' perceptions of patients' fears and concerns about insulin.

\section{Results}

\section{Characteristics of participants}

A total of 4,938 people with T2D were selected and agreed to complete the survey. The survey was finally completed by 590 people with T2D: 388 of these respondents had been treated with basal insulin (see Table 1 for further

Table I Demographics of people with type 2 (T2D) diabetes and physicians

\begin{tabular}{|c|c|}
\hline \multicolumn{2}{|l|}{ People with T2D } \\
\hline \multicolumn{2}{|l|}{ All respondents $(n=590)$} \\
\hline Male/female, n (\%) & $373(63.2) / 217(36.8)$ \\
\hline \multicolumn{2}{|l|}{ Age, n (\%) } \\
\hline$<50$ years & I I $8(20.0)$ \\
\hline$\geq 50$ to $\leq 59$ years & $153(25.9)$ \\
\hline$\geq 60$ years & $319(54.1)$ \\
\hline Retired/active employment, n (\%) & $281(47.6) / 224(37.9)$ \\
\hline \multicolumn{2}{|l|}{ Duration of T2D diagnosis, $\mathrm{n}(\%)$} \\
\hline$>25$ years & $45(7.6)$ \\
\hline $25-15$ years & $103(17.5)$ \\
\hline $15-10$ years & $269(45.6)$ \\
\hline$<10$ years & $173(29.3)$ \\
\hline \multicolumn{2}{|c|}{ Respondents treated with basal insulin $(n=388)$} \\
\hline Male/female, n (\%) & $250(64.4) / / 38(35.6)$ \\
\hline \multicolumn{2}{|c|}{ Duration of treatment with basal insulin, $\mathrm{n}(\%)$} \\
\hline $2-24$ months & $100(25.8)$ \\
\hline$>2$ to $<6$ years & $139(35.8)$ \\
\hline$\geq 6$ years & $149(38.4)$ \\
\hline \multicolumn{2}{|l|}{ Physicians } \\
\hline \multicolumn{2}{|l|}{ All respondents $(n=130)$} \\
\hline Diabetologists/endocrinologists, n (\%) & $65(50.0)$ \\
\hline General practitioners, n (\%) & $65(50.0)$ \\
\hline \multicolumn{2}{|l|}{ Age, n (\%) } \\
\hline$<35$ years & $14(10.8)$ \\
\hline $35-45$ years & $14(10.8)$ \\
\hline $46-50$ years & $15(11.5)$ \\
\hline $5 \mathrm{I}-55$ years & $22(16.9)$ \\
\hline$\geq 56$ years & $65(50.0)$ \\
\hline \multicolumn{2}{|l|}{ Duration of practicing medicine, $\mathrm{n}(\%)$} \\
\hline$<10$ years & $25(19.2)$ \\
\hline II-20 years & $29(22.3)$ \\
\hline$>20$ years & $76(58.4)$ \\
\hline \multicolumn{2}{|l|}{ Diabetologists/endocrinologists $(n=65)$} \\
\hline \multicolumn{2}{|l|}{ Location of practice, $\mathrm{n}(\%)$} \\
\hline Hospital & $22(33.8)$ \\
\hline Community & $24(36.9)$ \\
\hline Hospital and community & $19(29.2)$ \\
\hline
\end{tabular}


demographic details). All 590 respondents completed all of the survey questions.

A total of 4,905 physicians were contacted, and 197 agreed to participate. A total of 130 physicians were interviewed: 65 diabetologists/endocrinologists and 65 general practitioners (see Table 1 for further demographic details).

\section{Patients' feelings and perceptions about insulin therapy}

Mean scores (on a 10-point Likert scale; see Table 2) for negative feelings of guilt, distress, and detachment were 2.8, 3.1 , and 2.9, respectively, in respondents who had received insulin for 2-24 months. Respective mean scores were 3.8, 5.2, and 3.4 in insulin-naïve respondents who were receiving oral antidiabetic drugs. Mean scores for positive feelings of reassurance and willingness were 6.6 and 5.7, respectively, in those who had received insulin for 2-24 months, and 4.5 and 2.6 in insulin-naïve respondents receiving oral glucoselowering drugs (Table 2). The negative perception that insulin therapy was a sign of disease progression was held by $22 \%$ of respondents who had received insulin for 2-24 months and $68 \%$ of insulin-naïve respondents receiving oral glucoselowering drugs. The negative perception that insulin was associated with more inherent restrictions was held by $36 \%$ and $60 \%$ of respondents from these two respective groups (Table 3 ). Insulin was perceived to be effective by $49 \%$ of respondents who had received insulin for 2-24 months and by $21 \%$ of insulin-naïve respondents on oral glucose-lowering drugs (Table 3).

Nearly two-thirds of respondents who had transitioned to insulin reported the experience of starting insulin therapy as having been less difficult overall than they had imagined (Figure 1).

\section{Physicians' perceptions about insulin therapy}

When physicians were questioned regarding their perceptions of initiating insulin therapy in patients with T2D (several possible answers), the most frequent responses chosen were that insulin was an "effective treatment (improved glycemic control, fewer complications)," a "sign of disease progression" (especially by general practitioners), and "a more restrictive treatment (self-injection, increased risk of hypoglycemia, and the need for self-monitoring of blood glucose levels)." A total of $38 \%$ of diabetologists/endocrinologists and $22 \%$ of general practitioners perceived insulin initiation to be "an inevitable stage in the disease," and $34 \%$ and $20 \%$, respectively, considered insulin to be a "treatment with risk of hypoglycemia" (Table 4).

\section{Fears about initiating insulin therapy}

When rating the main fears that they thought a patient with T2D would have when initiating insulin therapy, $80 \%$ of physicians thought patients would fear injections and $26 \%$ thought patients would fear diabetes-related complications (Table 5). Corresponding percentages in 100 patients who had been using insulin for 2-24 months were $21 \%$ and $44 \%$.

Among the health care professionals, diabetologists/ endocrinologists and general practitioners shared similar concerns. Noticeably, despite the fears expressed by respondents with T2D, 69\% of all respondents receiving insulin reported trusting their doctor's recommendation to initiate insulin treatment.

Table 2 Feelings relating to insulin treatment in 590 patients with type 2 diabetes using a Likert scale (I [least likely] to 10 [most likely])

\begin{tabular}{|c|c|c|c|c|c|c|}
\hline & \multirow{3}{*}{$\begin{array}{l}\text { Patients on } \\
\text { oral glucose- } \\
\text { lowering drugs, } \\
\mathrm{n}=202^{\mathrm{a}}\end{array}$} & \multicolumn{5}{|c|}{ Patients taking insulin $n=\mathbf{3 8 8}$} \\
\hline & & \multirow{2}{*}{$\begin{array}{l}\begin{array}{l}\text { Before } \\
\text { initiation }\end{array} \\
2-24 \text { months, } \\
n=100\end{array}$} & \multirow{2}{*}{$\begin{array}{l}\text { At initiation }{ }^{c} \\
\begin{array}{l}2-24 \text { months, } \\
n=100\end{array}\end{array}$} & \multicolumn{3}{|l|}{ After initiation $^{d}$} \\
\hline & & & & $\begin{array}{l}2-24 \text { months, } \\
n=100\end{array}$ & $\begin{array}{l}>2 \text { to }<6 \text { years, }{ }^{e} \\
n=139\end{array}$ & $\begin{array}{l}\geq 6 \text { years, } \\
n=149\end{array}$ \\
\hline Guilt & $3.8 \pm 3.3$ & $3.8 \pm 3.3$ & $3.6 \pm 3.2$ & $2.8 \pm 2.9$ & $3.7 \pm 3.3$ & $2.6 \pm 2.9$ \\
\hline Distress & $5.2 \pm 3.5$ & $4.5 \pm 3.1$ & $4.4 \pm 3.1$ & $3.1 \pm 2.9$ & $4.1 \pm 3.2$ & $3.0 \pm 2.7$ \\
\hline Detachment & $3.4 \pm 3.2$ & $3.2 \pm 3.3$ & $2.9 \pm 3.1$ & $2.8 \pm 3.2$ & $2.8 \pm 3.0$ & $2.9 \pm 3.2$ \\
\hline Reassurance & $4.5 \pm 3.0$ & $5.1 \pm 2.9$ & $5.5 \pm 3.0$ & $6.6 \pm 2.6$ & $6.9 \pm 2.3$ & $6.6 \pm 2.7$ \\
\hline Willingness & $2.6 \pm 2.9$ & $4.4 \pm 3.2$ & $4.6 \pm 3.2$ & $5.7 \pm 2.9$ & $6.3 \pm 2.9$ & $6.3 \pm 2.9$ \\
\hline
\end{tabular}

Notes: Data are means \pm SD. Questions dealing with recall of feelings before and at initiation ( $b$ and $c$ ) are shown only for patients treated with insulin for $\leq 24$ months to limit memory bias. aLet us now talk about insulin treatments. How would you describe the nature and intensity of your feelings about this treatment? before receiving insulin treatment, how would you describe the nature and intensity of your feelings about this treatment? 'At the time of the initial prescription of your insulin treatment, how did you feel in nature and intensity about your feelings about this insulin treatment? 'Finally, today, how would you describe the nature and intensity of your feelings about this treatment? ${ }^{\text {eC }}$ urrent insulin-treatment duration. 
Table 3 Perceptions related to insulin treatment in 590 patients with type 2 diabetes

\begin{tabular}{|c|c|c|c|c|c|}
\hline & \multirow{3}{*}{$\begin{array}{l}\text { Patients on oral } \\
\text { glucose-lowering } \\
\text { drugs, } \mathrm{n}=\mathbf{2 0 2}^{\mathrm{a}}\end{array}$} & \multicolumn{4}{|c|}{ Patients taking insulin, $n=388$} \\
\hline & & \multirow{2}{*}{$\begin{array}{l}\text { Before initiation }^{b} \\
2-24 \text { months, }^{d} \\
n=100\end{array}$} & \multicolumn{3}{|l|}{ After initiation ${ }^{c}$} \\
\hline & & & $\begin{array}{l}\text { 2-24 months, }{ }^{d} \\
n=100\end{array}$ & $\begin{array}{l}>2 \text { to }<6 \text { years, } \\
\mathrm{n}=139\end{array}$ & $\begin{array}{l}\geq 6 \text { years, } \\
n=149\end{array}$ \\
\hline Sign of disease progression & $138(68)$ & $54(54)$ & $22(22)$ & $41(29)$ & $34(23)$ \\
\hline $\begin{array}{l}\text { More restrictive treatment (self-injection, } \\
\text { increased risk of hypoglycemia, and need for } \\
\text { self-monitoring of blood-glucose levels) }\end{array}$ & $122(60)$ & $5 I(5 I)$ & $36(36)$ & $50(36)$ & $46(31)$ \\
\hline Sign of transition to true diabetes & $110(54)$ & $37(37)$ & $23(23)$ & $22(16)$ & $23(15)$ \\
\hline $\begin{array}{l}\text { Treatment with higher social impact (disease } \\
\text { more difficult to conceal, fewer social } \\
\text { interactions and travel) }\end{array}$ & $66(33)$ & $32(32)$ & $28(28)$ & $39(28)$ & $40(27)$ \\
\hline Treatment with risk of hypoglycemia & $49(24)$ & $36(36)$ & $19(19)$ & $37(27)$ & $42(28)$ \\
\hline $\begin{array}{l}\text { Flexible treatment with possibility of } \\
\text { adapting doses according to need }\end{array}$ & $43(21)$ & $29(29)$ & $39(39)$ & $53(38)$ & $65(44)$ \\
\hline Inevitable stage of disease & $43(21)$ & $45(45)$ & $4 I(4 I)$ & $63(45)$ & $57(38)$ \\
\hline $\begin{array}{l}\text { Effective treatment (improved glycemic } \\
\text { control, fewer complications) }\end{array}$ & $42(2 I)$ & $47(47)$ & $49(49)$ & $67(48)$ & $67(45)$ \\
\hline Treatment with risk of weight gain & $32(16)$ & $40(40)$ & $43(43)$ & $59(42)$ & $51(34)$ \\
\hline Other & II (5) & $3(3)$ & $2(2)$ & $2(1)$ & $3(2)$ \\
\hline
\end{tabular}

Notes: Data are $\mathrm{n}(\%)$ of patients. Question b, dealing with recall of perceptions before and at initiation, is shown only for patients treated with insulin for $\leq 24$ months to

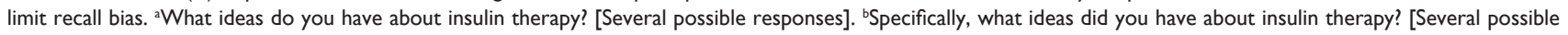
responses]. 'Specifically, what are your perceptions of your insulin treatment today? [Several possible responses]. ${ }^{d}$ Current insulin-treatment duration.

\section{Wording used to present insulin therapy}

\section{at first mention}

Both respondents with $\mathrm{T} 2 \mathrm{D}$ and physicians were questioned about the wording that was used by the physician when first mentioning insulin therapy. When describing insulin therapy at first mention, $42 \%-80 \%$ of physicians indicated that they had used such phrases as "an option allowing better control of the disease" and "a treatment option to consider one day."

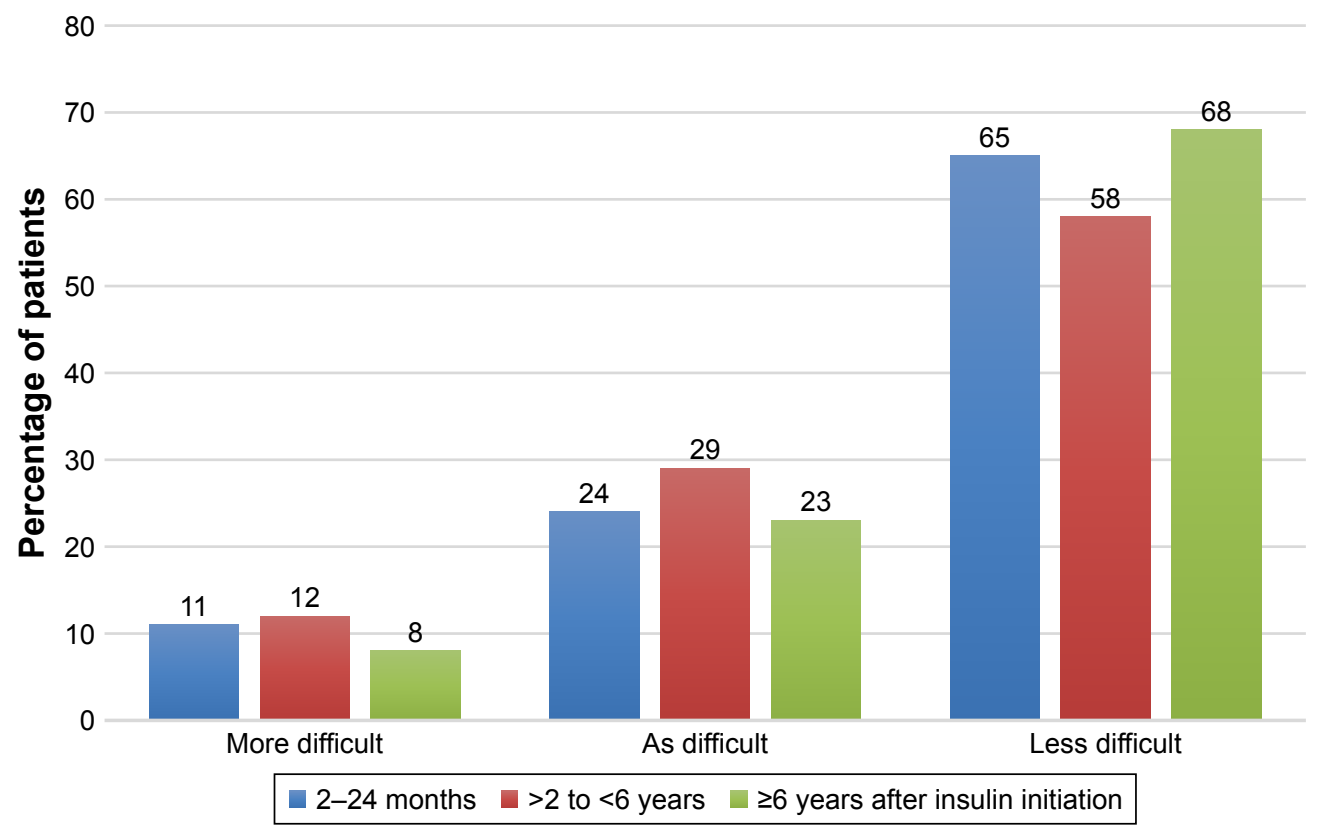

Figure I Patients' current experiences vs previous perceptions of starting insulin therapy.

Notes: The question put to the 388 patients who received insulin therapy was "In hindsight and compared to what you imagined before this type of treatment, how does the experience of starting insulin appear to you globally?" Data were obtained for the three patient groups: 100 patients had received insulin for $2-24$ months, 139 patients $>2$ to $<6$ years, and 149 patients $\geq 6$ years. 
Table 4 Physicians' perceptions of insulin therapy

\begin{tabular}{|c|c|c|c|}
\hline & $\begin{array}{l}\text { All physicians, } \\
n=130\end{array}$ & $\begin{array}{l}\text { Diabetologists, } \\
\text { endocrinologists, } \\
n=65\end{array}$ & $\begin{array}{l}\text { General } \\
\text { practitioners, } \\
\mathrm{n}=65\end{array}$ \\
\hline Effective treatment (improved glycemic control, fewer complications) & $70(54)$ & $36(55)$ & $34(52)$ \\
\hline Sign of disease progression & $55(42)$ & $17(26)$ & $38(58)$ \\
\hline $\begin{array}{l}\text { More restrictive treatment (self-injection, increased risk of hypoglycemia, } \\
\text { and need for self-monitoring of blood-glucose levels) }\end{array}$ & $49(38)$ & $26(40)$ & $23(35)$ \\
\hline Inevitable stage of disease & $39(30)$ & $25(38)$ & $14(22)$ \\
\hline Treatment with risk of hypoglycemia & $35(27)$ & $22(34)$ & $13(20)$ \\
\hline Treatment with risk of weight gain & $35(27)$ & $20(31)$ & $15(23)$ \\
\hline Flexible treatment with possibility of adapting dose according to patient's needs & $28(22)$ & $15(23)$ & $13(20)$ \\
\hline $\begin{array}{l}\text { Treatment with greater social impact (disease more difficult to conceal, social } \\
\text { interactions and travel less frequent) }\end{array}$ & $24(18)$ & II (I7) & $13(20)$ \\
\hline The sign of a transition to true diabetes & $8(6)$ & $3(5)$ & $5(8)$ \\
\hline Other & 0 & 0 & 0 \\
\hline
\end{tabular}

Notes: Question posed was "How would you rate the transition from oral glucose-lowering therapy to insulin therapy for a patient with Type 2 diabetes?" (Several possible answers). Data are $\mathrm{n}(\%)$ of physicians.

Of respondents with $\mathrm{T} 2 \mathrm{D}$ who had been receiving insulin for 2-24 months, $47 \%$ recalled that the physician used such phrases as "an option allowing better control of the disease" or "an inevitable option in view of the evolution of the disease" when insulin therapy was first mentioned. Diabetologists and general practitioners used the same messages overall, although $80 \%$ of diabetologists and $62 \%$ of general practitioners highlighted the better disease control that would be achieved with insulin (Table 6).

\section{Timing of first mention of insulin therapy}

Both people with T2D and physicians were questioned regarding the timing of when insulin therapy was first mentioned. For the 100 respondents who initiated insulin treatment 2-24 months before the survey (several possible answers), $26 \%$ recalled that their physician had started to talk about insulin therapy for the first time when the physician suggested initiating insulin therapy, $13 \%$ recalled that it was at diagnosis, $16 \%$ when an additional oral treatment was added, $12 \%$ when the first treatment was prescribed, $11 \%$ when an injectable therapy other than insulin was prescribed, $18 \%$ at another time, and $4 \%$ did not remember. For the 130 physician respondents (several possible answers), $76 \%$ recalled that they referred to insulin therapy most often when oral therapy was intensified, $49 \%$ estimated that it was at the start of insulin therapy, 39\% when prescribing an injectable therapy other than insulin, 19\% at the time of diabetes diagnosis, and $3 \%$ at another time.

Table 5 Patients' fears associated with starting insulin therapy

\begin{tabular}{|c|c|c|c|c|}
\hline & \multirow{2}{*}{$\begin{array}{l}\text { Patients: your fears }^{\mathrm{a}} \\
2-24 \text { months, }^{\mathrm{c}} \mathrm{n}=100\end{array}$} & \multicolumn{3}{|c|}{ Physicians: fears of your patients ${ }^{b}$} \\
\hline & & $\begin{array}{l}\text { All, } \\
n=130\end{array}$ & $\begin{array}{l}\text { Diabetologists, } \\
\text { endocrinologists, } \\
n=65\end{array}$ & $\begin{array}{l}\text { General } \\
\text { practitioners, } \\
n=65\end{array}$ \\
\hline Fear of complications related to the disease (amputation, blindness) & $44(44)$ & $34(26)$ & $19(29)$ & $15(23)$ \\
\hline Fear of lifelong treatment & $36(36)$ & $65(50)$ & $31(48)$ & $34(52)$ \\
\hline Fear of complications related to insulin (weight gain, hypoglycemia) & $42(42)$ & $56(43)$ & $35(54)$ & $21(32)$ \\
\hline Feelings of failure with my past treatments/efforts & $25(25)$ & $29(22)$ & $15(23)$ & $14(22)$ \\
\hline Fear of stinging and/or injecting myself & $2 \mathrm{I}(2 \mathrm{I})$ & $104(80)$ & $50(77)$ & $54(83)$ \\
\hline Fear of aggravation of disease & $17(17)$ & $25(19)$ & $16(25)$ & $9(14)$ \\
\hline Other fears & $4(4)$ & $5(4)$ & $3(5)$ & $2(3)$ \\
\hline No answer & 0 & 0 & 0 & 0 \\
\hline
\end{tabular}

Notes: Questions were addressed to patients who had been receiving insulin therapy for $\leq 24$ months and to physicians (several possible answers). Data are $\mathrm{n}$ (\%) of patients/physicians. a What were your main fears? ' ${ }^{b}$ What are the main fears of your patients starting insulin treatment? 'Current insulin-treatment duration. 
Table 6 Wording used by physicians to describe insulin therapy at first mention

\begin{tabular}{|c|c|c|c|c|}
\hline & \multirow{2}{*}{$\begin{array}{l}\text { Patients' answers }^{\mathrm{a}} \\
2-24 \text { months, }^{\mathrm{c}} \\
\mathrm{n}=100\end{array}$} & \multicolumn{3}{|c|}{ Physicians' answers $^{\mathbf{b}}$} \\
\hline & & $\begin{array}{l}\text { All, } \\
n=130\end{array}$ & $\begin{array}{l}\text { Diabetologists, } \\
\text { endocrinologists, } \\
n=65\end{array}$ & $\begin{array}{l}\text { General } \\
\text { practitioners, } \\
\mathrm{n}=65\end{array}$ \\
\hline An inevitable option in view of the evolution of the disease & $47(47)$ & $55(42)$ & $25(38)$ & $30(46)$ \\
\hline $\begin{array}{l}\text { An option allowing better control of the disease, more effective than } \\
\text { other treatments }\end{array}$ & $47(47)$ & $92(7 I)$ & $52(80)$ & $40(62)$ \\
\hline A more adaptable/flexible treatment (dose adjustment to blood glucose) & $29(29)$ & $26(20)$ & $10(15)$ & $16(25)$ \\
\hline A treatment option to consider one day & $28(28)$ & $65(50)$ & $38(58)$ & $27(42)$ \\
\hline The next step of treatment & II (II) & $33(25)$ & $18(28)$ & $15(23)$ \\
\hline An option to postpone as late as possible & $15(15)$ & II (8) & $3(5)$ & $8(12)$ \\
\hline A sanction/threat in case of improper regularity of your medications & $4(4)$ & $22(17)$ & $8(I 2)$ & $14(22)$ \\
\hline I do not remember & $\mathrm{I}(\mathrm{I})$ & NA & NA & NA \\
\hline
\end{tabular}

Notes: Data are $\mathrm{n}(\%)$ of patients or physicians. ${ }^{2}$ Question addressed to patients who had been receiving insulin therapy for $\leq 24$ months (several possible answers): "In what terms did your doctor tell you about insulin?" 'Question addressed to physicians (several possible answers): "At first mention, what terms do you use to tell your patients about insulin?" 'Current insulin-treatment duration.

Abbreviation: NA, not applicable.

\section{Time lag to acceptance of insulin treatment}

The time lag to the acceptance and start of insulin treatment was investigated in both people with T2D and physicians. For the 100 respondents with T2D who initiated insulin treatment 2-24 months before the survey, $49 \%$ estimated that they had needed 1 or 2 weeks to agree to start treatment with insulin after their physician had notified them of the need to switch therapy, $13 \%$ estimated this time at between 2 and 4 weeks, $16 \%$ between 1 and 2 months, $15 \%$ between 3 and 6 months, $6 \% \geq 6$ months, and $1 \%$ did not answer. For the 130 physician respondents, $16 \%$ estimated that the time needed for a patient to accept the idea of insulin treatment was 1 or 2 weeks, $9 \%$ estimated it was between 2 and 4 weeks, $9 \%$ between 1 and 2 months, $47 \%$ between 3 and 6 months, 12\% $\geq 6$ months, and $7 \%$ did not answer.

\section{Overall information about insulin therapy}

Overall, most respondents with T2D (92\%-97\%) who had received insulin for 2-24 months reported that general information about insulin (why they need to switch to insulin, the role of insulin and how it works, and glycemic targets), pen manipulation, and adjustment of insulin doses had been mentioned when insulin therapy was first prescribed. Of those receiving insulin for 2-24 months, $66 \%$ reported that information about managing insulin on a daily basis had been mentioned at the same time as insulin was prescribed. Retrospectively, people with T2D found the adjustment of insulin doses to be the most difficult aspect of starting insulin therapy ( $73 \%$ of respondents, Table 7 ).

\section{Discussion}

To our knowledge, this is the first survey to evaluate the perceptions of French people with T2D and their health care providers toward initiating insulin therapy. The answers to the survey questions revealed differences between physicians and patients and between insulin-naïve respondents and insulin-treated respondents, as reported in other studies. ${ }^{3,17}$

Physicians regarded the initiation of insulin in a positive light, and saw it as being effective and associated with improved glycemic control and fewer complications. However, when physicians suggested a transition to insulin, people with T2D perceived this negatively and saw it as an indication that their disease had progressed. The most striking discrepancy in patient/physician perceptions was undoubtedly the doctors' perception that patients would be especially apprehensive of injections, whereas this was much less of an issue for patients. People with T2D who had already transitioned to insulin recalled that the fear of injections was only one fear/concern among many at the time of transition, and that they were more concerned about the complications of insulin therapy (hypoglycemia, weight gain). Leslie et al also reported that although the first reason most people offered to explain their resistance to initiating insulin was that injections hurt, this was often the most easily expressed and not the most important reason for not wanting to take insulin. ${ }^{11}$

Despite these and various other concerns that could affect their transition to insulin, people with T2D expressed no concerns that reflected a lack of trust in their physician's 
Table 7 Information delivered and difficulties encountered at time of insulin initiation

\begin{tabular}{|c|c|c|c|c|}
\hline & $\begin{array}{l}\text { General } \\
\text { information } \\
\text { about insulin }^{\mathrm{a}}\end{array}$ & Pen manipulation ${ }^{b}$ & $\begin{array}{l}\text { Adjustment } \\
\text { of insulin } \\
\text { doses }^{c}\end{array}$ & $\begin{array}{l}\text { Live with } \\
\text { on daily } \\
\text { basis }^{\text {d }}\end{array}$ \\
\hline $\begin{array}{l}\text { When insulin was prescribed to you, what elements were presented to you } \\
\text { in one way or another? (several possible answers) }\end{array}$ & $97 \%$ & $95 \%$ & $92 \%$ & $66 \%$ \\
\hline $\begin{array}{l}\text { How would you judge the usefulness of this information at the beginning of } \\
\text { the insulin treatment? Indicate which information you consider a priority } \\
\text { (several possible answers) }\end{array}$ & $93 \%$ & $87 \%$ & $90 \%$ & $78 \%$ \\
\hline $\begin{array}{l}\text { In retrospect, what did you find most difficult when you started your } \\
\text { treatment? (Several possible answers) }\end{array}$ & $62 \%$ & $57 \%$ & $73 \%$ & $57 \%$ \\
\hline
\end{tabular}

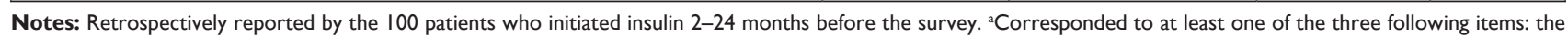
reasons for switching to insulin, role of insulin and how it works, and blood-glucose targets you need to achieve. ${ }^{b}$ Corresponded to at least one of the four following items: grip/presentation of pen; where to inject and when, injection sites and timing; how to carry out my injection/purge, injection time; and how to conserve my insulin/rules of conservation of insulin. 'Corresponded to at least one of the four following items: how to perform blood-glucose monitoring with the pen and analyze the results, how to adapt my doses of insulin, what situations increase the risk of hypoglycemia, and what to do in case of hypoglycemia. ${ }^{\mathrm{d}}$ Corresponded to at least one of the three following items: what to do if you forget, impact on management of my physical activity, and impact on the management of my food.

judgment that this form of therapy was necessary, with $69 \%$ of all insulin-treated respondents with T2D stating that they trusted their doctor when insulin treatment was first proposed. The findings of the DAWN2 study, reported by Reach et al, also emphasized this notion of trust toward physicians, with most people with diabetes prepared to follow the recommendations of their practitioner. ${ }^{2}$ In fact, $72 \%$ of people with T2D receiving oral treatment and $61 \%$ of those following dietary and lifestyle measures reported being ready to begin insulin if it was prescribed. ${ }^{2}$

Once the transition to insulin had actually taken place, two-thirds of respondents with T2D reported that they had experienced fewer difficulties than they had originally feared. This is in agreement with the findings of several other studies. For example, Bahrmann et al reported that insulinnaïve people with diabetes had a significantly greater negative attitude toward insulin therapy than people already on insulin. ${ }^{3}$ In a qualitative study in six people with T2D who had recently changed from oral medication to self-administered insulin injections, ${ }^{18}$ people reported a range of initial reactions (from shock and anger to relief); however, their perceptions of insulin changed over time, with some people eventually accepting insulin and feeling empowered. ${ }^{18}$

In the current study, the greatest concerns for people with T2D prior to initiating insulin therapy included worsening of the disease and treatment-related restrictions (eg, need for injections and self-monitoring of blood glucose levels; Table 3). However, after people transitioned to and continued with insulin treatment, its effectiveness became one of the more important perceptions. In the INSIGHT study, which investigated an early "insulinization" strategy compared with an optimized oral glucose-lowering regimen without insulin, the insulin-treated group experienced significantly greater improvements in treatment satisfaction and quality of life, together with lower glycated hemoglobin. ${ }^{19}$

The current survey indicates that doctors focus more on the technical aspects of insulin administration when discussing the initiation of insulin therapy, whereas people with T2D focus on the impact of this therapy on their everyday life. Other researchers have also reported that people considered they were provided with sufficient information regarding the technical aspects of insulin therapy, but that information regarding other aspects of insulin therapy was lacking. ${ }^{17}$ Health care providers want people with T2D to transition to insulin because it is associated with an improvement in glycemic control, as well as the prevention of complications. Doctors envision a point in the future in which their insulin-treated patients are free from diabetic complications. However, people with T2D are more preoccupied with their immediate fears and concerns, and they perceive the transition to insulin as an indication that they already have or are more likely to have these complications.

It is thus important that health care providers seek to better understand the fears and concerns of people with T2D initiating insulin therapy and then take the best possible approach to minimize them. ${ }^{4,5,18,20}$ The relatively satisfactory after-the-fact acceptance of insulin by people with T2D should in no way diminish efforts aimed at reducing the difficulties people perceive at the time of transitioning from oral antidiabetic to insulin therapy.

The strengths of this survey include the collection of information from different groups (including physicians [specialists and generalists] and people with T2D [insulinnaïve and insulin-treated]), the collection of information by an independent agency that specializes in conducting surveys, the large number of questions asked of people with T2D, and 
the analysis of similar questions answered by both patients and physicians.

This survey also has several limitations. Although the questionnaires have not been formally validated (hence reproducibility and sensitivity have not been established), they were designed by an expert group comprising diabetologists and general practitioners, as well as a nurse and a psychologist (the latter two probably having closer relationships with patients than doctors do); however, there was no participation of persons with T2D in the survey design. Nevertheless, participant acceptance of the survey was high $(100 \%)$. In addition, the survey was retrospective and crosssectional in design, and the transition of patients from oral antidiabetics to insulin therapy was not explored longitudinally or sequentially. In addition, there was no justification for the choice of sample size. Any event of this magnitude in the life of a person with T2D is certainly memorable, and it is important to distinguish between the recollection of a previous experience and what the person actually experienced at the time. This survey did not investigate the sequential experiences of people with $\mathrm{T} 2 \mathrm{D}$ at the point their physician informed them that they needed to transition to insulin, the transition itself, life immediately after the transition, or finally the long-term experience of being on insulin. However, efforts were made to minimize recall bias by limiting the gap between the person's actual experience and their recollection of transitioning to insulin to $\leq 24$ months. Nevertheless, this delay will have generated a heterogeneity of life experiences with insulin, with some people with T2D having only recently been introduced to this therapy and others having longer experience with its use. In addition, analyses of the survey results were descriptive only. Although the use of an Internet survey may have increased the number of respondents with $\mathrm{T} 2 \mathrm{D}$, this had the drawback that there was no certainty that the questions were answered accurately. Some people with T2D may not commonly use computers or the Internet, and thus respondents were probably those with the appropriate computer skills. Using a focus group to explore in more depth some of the concepts investigated - especially the finding that the perception of fears differed between physicians and people with T2D - would be interesting. The marked difference in the perception of fear of stinging and/or injecting ( $21 \%$ of patients vs $80 \%$ of physicians) is one finding that certainly requires further investigation. Finally, the number of health care provider respondents was lower than the number of respondents with $\mathrm{T} 2 \mathrm{D}$, and, as the health care providers included both nonspecialists and specialists in diabetes, they did not represent a single group.

\section{Conclusion}

This cross-sectional survey highlighted discrepancies between the perceptions of French people with T2D and those of health care providers with respect to the transition to insulin therapy. People with T2D who were established on insulin therapy reported that the transition to insulin had been less difficult than they had imagined. Nevertheless, people with T2D should still be supported during this transition so that any fears regarding their disease and its treatment can be minimized.

\section{Practice implications}

The care relationship between a person with T2D and their physician must consider the persons' biomedical requirements and perceptions regarding the difficulties he/she will experience when transitioning to insulin. With these difficulties in mind, health care providers will be able to intervene to minimize the person's concerns at the time of transition. People with T2D who have already successfully transitioned to insulin could provide support to those who are about to initiate insulin therapy. The development of this peer-support system and its inclusion as part of the existing management team could play an important role in establishing an alliance between health care professionals and people with T2D.

\section{Data statement}

The data sets generated and/or analyzed during the current survey are not publicly available. All the relevant data are included in this published article and the Supplementary material.

\section{Acknowledgments}

The authors would like to thank Arnaud Zegierman and Amandine Messina (ViaVoice, Paris, France) for conducting the patient and physician interviews and managing the online surveys. The authors would also like to thank Jacques Vandangeon (general practitioner), Agnès Sola-Gazagnès (diabetologist), Sylvie Sebillet (nurse), and Veronique Klopp (psychologist) for their participation in the expert group for this survey. In addition, the authors would like to acknowledge Hervé Maisonneuve and Gill Gummer ( $\mathrm{Rx}$ Communications, Mold, UK) for medical writing assistance with the preparation of this manuscript. This work was funded by Eli Lilly and Company.

\section{Disclosure}

EC has received honoraria and medical training from Eli Lilly and Company, Novo Nordisk, and Sanofi Aventis. 
J-DL has received honoraria and medical training from Eli Lilly, Merck, MSD, Novo Nordisk, and Sanofi. CM, IB, MLB, and FB are full-time employees of and minor shareholders in Eli Lilly. The authors report no other conflicts of interest in this work.

\section{References}

1. Inzucchi SE, Bergenstal RM, Buse JB, et al. Management of hyperglycemia in type 2 diabetes: a patient-centered approach: position statement of the American Diabetes Association (ADA) and the European Association for the Study of Diabetes (EASD). Diabetes Care. 2012; 35(6):1364-1379.

2. Reach G, Consoli SM, Halimi S, et al. The multinational second diabetes, attitudes, wishes and needs study: results of the French survey. Patient Prefer Adherence. 2015;9:289-297.

3. Bahrmann A, Abel A, Zeyfang A, et al. Psychological insulin resistance in geriatric patients with diabetes mellitus. Patient Educ Couns. 2014; 94(3):417-422.

4. Peragallo-Dittko V. Removing barriers to insulin therapy. Diabetes Educ. 2007;33(s3):60S-65S.

5. Rubin RR, Peyrot M. Psychological issues and treatments for people with diabetes. J Clin Psychol. 2001;57(4):457-478.

6. Polonsky WH, Fisher L, Guzman S, Villa-Caballero L, Edelman SV. Psychological insulin resistance in patients with type 2 diabetes: the scope of the problem. Diabetes Care. 2005;28(10):2543-2545.

7. Wang HF, Yeh MC. Psychological resistance to insulin therapy in adults with type 2 diabetes: mixed-method systematic review. J Adv Nurs. 2012;68(4):743-757.

8. Zambanini A, Newson RB, Maisey M, Feher MD. Injection related anxiety in insulin-treated diabetes. Diabetes Res Clin Pract. 1999; 46(3):239-246.

9. Peyrot M, Rubin RR, Lauritzen T, et al. Resistance to insulin therapy among patients and providers: results of the cross-national diabetes attitudes, wishes, and needs (DAWN) study. Diabetes Care. 2005;28(11): 2673-2679

10. Krall J, Gabbay R, Zickmund S, Hamm ME, Williams KR, Siminerio L. Current perspectives on psychological insulin resistance: primary care provider and patient views. Diabetes Technol Ther. 2015;17(4): $268-274$.
11. Leslie C, Satin-Rapaport W, Matheson D, Stone R, Enfield G. Psychological insulin resistance: a missed diagnosis. Diabetes Spectr. 1994; 7:52-57.

12. Brod M, Kongsø JH, Lessard S, Christensen TL. Psychological insulin resistance: patient beliefs and implications for diabetes management. Qual Life Res. 2009;18(1):23-32.

13. Petrak F, Herpertz S, Stridde E, Pfützner A. Psychological insulin resistance in type 2 diabetes patients regarding oral antidiabetes treatment, subcutaneous insulin injections, or inhaled insulin. Diabetes Technol Ther. 2013;15(8):703-711.

14. United Kingdom Prospective Diabetes Study Group. United Kingdom Prospective Diabetes Study (UKPDS). 13: relative efficacy of randomly allocated diet, sulphonylurea, insulin, or metformin in patients with newly diagnosed non-insulin dependent diabetes followed for three years. BMJ. 1995;310(6972):83-88.

15. Holt RI, Nicolucci A, Kovacs Burns K, et al. Diabetes attitudes, wishes and needs second study (DAWN2 ${ }^{\mathrm{TM}}$ ): cross-national comparisons on barriers and resources for optimal care - healthcare professional perspective. Diabet Med. 2013;30(7):789-798.

16. Nicolucci A, Kovacs Burns K, Holt RI, et al. Diabetes attitudes, wishes and needs second study (DAWN2 ${ }^{\mathrm{TM}}$ ): cross-national benchmarking of diabetes-related psychosocial outcomes for people with diabetes. Diabet Med. 2013;30(7):767-777.

17. Berard L, Bonnemaire M, Mical M, Edelman S. Insights into optimal basal insulin titration in type 2 diabetes: results of a quantitative survey. Diabetes Obes Metab. 2018;20(2):301-308.

18. Morris JE, Povey RC, Street CG. Experiences of people with type 2 diabetes who have changed from oral medication to self-administered insulin injections. Pract Diab Int. 2005;22(7):239-243.

19. Houlden R, Ross S, Harris S, Yale JF, Sauriol L, Gerstein HC. Treatment satisfaction and quality of life using an early insulinization strategy with insulin glargine compared to an adjusted oral therapy in the management of type 2 diabetes: the Canadian INSIGHT study. Diabetes Res Clin Pract. 2007;78(2):254-258.

20. Spollett GR. Insulin initiation in type 2 diabetes: what are the treatment regimen options and how can we best help patients feel empowered? $J$ Am Acad Nurse Pract. 2012;24(Suppl 1):249-259.
Patient Preference and Adherence

\section{Publish your work in this journal}

Patient Preference and Adherence is an international, peer-reviewed, open access journal that focuses on the growing importance of patient preference and adherence throughout the therapeutic continuum. Patient satisfaction, acceptability, quality of life, compliance, persistence and their role in developing new therapeutic modalities and compounds to optimize

\section{Dovepress}

clinical outcomes for existing disease states are major areas of interest for the journal. This journal has been accepted for indexing on PubMed Central. The manuscript management system is completely online and includes a very quick and fair peer-review system, which is all easy to use. Visit http://www. dovepress.com/testimonials.php to read real quotes from published authors. 